\title{
Promoting Interprofessional Collaboration: Pharmacy Students Teaching Current and Future Prescribers About Medicare Part D
}

\author{
Cindy J. Lai, MD; Amanda R. Smith, MPH; Marilyn R. Stebbins, PharmD; \\ Timothy W. Cutler, PharmD; and Helene L. Lipton, PhD
}

\begin{abstract}
BACKGROUND: Nearly all health professional students and prescribers, regardless of specialty, will care for older adults who are enrolled in or eligible for the Medicare Part D prescription drug benefit. Given the growing numbers of older adults, the increased burden of chronic disease, and the escalating costs of health care, health professional students and prescribers across disciplines should learn strategies to promote cost-effective prescribing and collaborate with pharmacists who are experts in medication use and costs.

OBJECTIVE: To describe and evaluate the impact of a statewide peer education program in which selected students at 7 California schools of pharmacy delivered a clinically relevant lecture on Part $D$ to a multidisciplinary audience of health professional students and prescribers.

METHODS: Trained pharmacy students delivered a case-based lecture on Medicare Part $D$ to other health professional students and prescribers throughout the state of California. An 11-item survey designed to evaluate (a) self-assessed Part D knowledge, (b) opinion of pharmacists' roles on the health care team, (c) intent to collaborate with pharmacists, and (d) awareness of cost-savings strategies to reduce patients' out-of-pocket drug costs was administered before and after the lecture. Pre-lecture versus post-lecture results were tested for statistical significance using the Wilcoxon signed-rank test with Bonferroni adjustment of alpha to 0.004 because of multiple comparisons.
\end{abstract}

RESULTS: From 0ctober 2008 through May 2010, trained students from 7 pharmacy schools gave 58 presentations to a total of 1,490 current or future prescribers, including 304 nurse practitioner students and 279 resident physicians. At baseline pre-lecture, self-rated knowledge of Medicare Part $D$ was generally poor; only $4.9 \%$ of respondents strongly agreed that "I understand the Medicare Part D benefit," and 6.6\% strongly agreed that they could "identify key Medicare Part D resources to help my patients." Nine of 11 survey items showed statistically significant improvement $(P<0.001)$, including all 4 items in the Part $D$ knowledge domain and all 5 items in the intent-to-collaborate domain (e.g., "I consult with pharmacists and/or pharmacy students about drug costs"). Outcomes were similar across the 7 schools.

CONCLUSION: At pre-lecture baseline, self-reported deficits in knowledge about Part $\mathrm{D}$ policy and drug cost-savings resources and strategies existed among medical, nursing and physician assistant students, resident physicians, and other health professionals. A pharmacy student-led peer education lecture can be used to bridge this gap, resulting in timely dissemination of geriatrics health policy information and increased awareness of pharmacists' roles and expertise in pharmaceutical health policy and patient care.

\section{J Manag Care Pharm. 2011;17(6):439-48}

Copyright $\odot 2011$, Academy of Managed Care Pharmacy. All rights reserved.

\section{What is already known about this subject}

- Since its implementation in 2006, Part D has been an important policy reform and has led to decreased out-of-pocket costs and expanded access to prescription drugs for vulnerable beneficiaries who need it most. However, this complex benefit has also confused patients and their health care providers. Despite the complexity of the benefit, few health care providers have had formal training in Part D. In 1 study conducted from November 2006 through June 2008, only 16\% of health professional students and resident physicians reported having had any formal coursework in Part D

- The majority of low-income Part D beneficiaries are not in the most cost-effective Part D plan. In 1 study, only 29\% of beneficiaries with a stand-alone Part D prescription drug plan were enrolled in the lowest-cost plan. Adding to the confusion, the passage of the Patient Protection and Affordable Care Act (PPACA) in 2010 enacted further modifications to Part D.

- A previous pilot study from a single site suggested that pharmacy student-led lectures improved interprofessional learners' selfassessed knowledge about Part D and attitudes toward professional collaboration, particularly with regard to pharmacists.

\section{What this study adds}

- This study is the first multisite investigation examining the impact of Medicare Part D training for current and future prescribers delivered by trained pharmacy students.

- A standardized, 1- to 2-hour lecture delivered by trained pharmacy students significantly improved outcomes for learners including (a) self-assessed Part D knowledge; (b) intent to collaborate with pharmacists regarding drug costs, drug selection, drug policy, formularies, and insurance plans; and (c) awareness of strategies to reduce patients' out-of-pocket drug costs. From baseline pre-lecture to post-lecture, the percentage of respondents agreeing with the statement "I understand the Medicare Part D benefit" increased from $4.9 \%$ to $64.1 \%$, and the percentage agreeing that "I can identify key Medicare Part D resources to help my patients" increased from $6.6 \%$ to $60.9 \%$.

- This interprofessional peer education program might be used as a model for future dissemination of critical and timely health policy information to a wide variety of health professionals and trainees. In the post-lecture survey, $98.3 \%$ of learners strongly or somewhat agreed that the peer-to-peer format was an effective way to provide education about Medicare Part D. 
A $\mathrm{t}$ an increasingly rapid pace, health policy legislation is changing the way that medicine is practiced. To ensure a properly trained health care workforce, accreditation organizations and medical education experts have indicated that health policy education, including content on cost-containment strategies, is needed at all levels. ${ }^{1-7}$ Teaching about Medicare Part D prescription drug benefit (Part D) legislation is particularly important in geriatric medicine due to the number of older adults affected by this policy. In 2011 alone, 2.8 million baby boomers will become eligible for Medicare. ${ }^{8}$ Many will enroll in Part D, and some of these Part D enrollees will be on limited incomes. ${ }^{8}$

Since its implementation in 2006, Part D has been an important policy reform and has led to decreased out-of-pocket costs and expanded access to prescription drugs for vulnerable beneficiaries who need it most. ${ }^{9}$ However, this complex benefit has also confused patients and their health care providers alike..$^{10,11}$ In 1 study conducted from November 2006 through June 2008 , only $16 \%$ of health professional students and resident physicians reported having had any formal coursework in Part D. ${ }^{12}$ Yet, at some point in their training or their careers, nearly all health professionals, regardless of specialty, will be caring for older adults who are enrolled in or are eligible for Part D. In addition, many Part D patients, especially low-income or other vulnerable patients, lack the knowledge and skills needed to select the least expensive plan that covers their medications. ${ }^{11,13}$ In 1 study, only $29 \%$ of beneficiaries with a stand-alone Part D prescription drug plan were enrolled in the lowest-cost plan. ${ }^{14}$ Adding to the confusion, the passage of the Patient Protection and Affordable Care Act (PPACA) in March 2010 enacted further modifications to Part D. ${ }^{15}$

With the continued escalation of drug prices and the concomitant out-of-pocket cost burden faced by older adults, ${ }^{16}$ health professionals need to be able to promote cost-effective medication use and access to appropriate prescription drug plans. The pharmacist, an expert in medication selection, use, and cost, can help navigate the Part $\mathrm{D}$ benefit. In a recent metaanalysis examining the roles and contributions of pharmacists' interventions, results revealed that pharmacists improve the quality of physicians' prescribing and provider understanding of their patients' adherence to medication regimens; ${ }^{17}$ thus, it seems appropriate to expose medical students and resident physicians to pharmacists' expertise and to emphasize the need for timely collaboration on Part D between prescribers and pharmacists.

Given the significant impact of Medicare Part D on patient care and the existing gap in knowledge about this health policy, we developed a statewide peer education program in which selected pharmacy students taught medical students, resident physicians, and other health professionals about Part D in 1- to 2-hour case-based, interactive lectures. We selected pharmacy students because of their expertise in cost-saving strategies and familiarity with Part D resources, as well as the proven effectiveness of peer teaching in other settings. ${ }^{18}$ Peer teaching is variably defined but generally refers to students teaching other students at the same or similar level in the same health professional school or discipline; we broadened this concept to include teaching of peers across any health professional school and resident physicians in training.

A previously published pilot study conducted at a single university campus showed that the lectures improved learners' self-assessed knowledge about Part D and attitudes toward professional collaboration, particularly with regard to pharmacists. ${ }^{12}$ To examine whether these pilot results could be replicated in more diverse sites, we expanded the program to 7 campuses, training selected pharmacy students from each of the 7 schools of pharmacy to deliver similar Part D lectures to additional groups of health professional trainees and physicians. The purpose of the present study was to describe and evaluate the impact of this statewide education program on learners' self-assessed knowledge of Medicare Part D, their awareness of Part D resources and medication cost containment strategies, their attitudes toward pharmacists, and their intention to collaborate with pharmacists in the future.

\section{Methods}

\section{Design}

The peer educator program was a major component of the Partners in D grant, a California statewide research program helping providers and underserved Medicare patients navigate Part D, led by pharmacy and medicine faculty at the University of California, San Francisco (UCSF). ${ }^{19}$ All 7 California schools of pharmacy in the Partners in D collaborative agreed to participate in the peer educator program. To measure the impact of the program, we used a pre/post design. Each of the 7 schools obtained institutional review board approval to participate in this research.

\section{Setting, Intervention, and Participants}

Through faculty champions at each of the 7 pharmacy schools, 4 pharmacy students from each school were selected and trained as peer educators, leading 1- to 2-hour lectures on Part D to multiprofessional audiences. We selected pharmacy students as peer educators because of their expertise in drug costs and the Part D benefit and to highlight the important role of the pharmacist in Part D-related patient care activities. Peer educators were selected through a competitive application process and were required to have completed a prerequisite course that included both Part D didactic coursework and a Part D community outreach component targeting vulnerable Medicare beneficiaries. After selection as peer educators, students participated in further training in public speaking in order to make the presentation interactive and clinically relevant to specific audiences. 
The major target audiences for the Part D lectures were current and future prescribers, with an emphasis on medical students, nurse practitioner students, and resident physicians. Some lectures included physician assistant students, osteopathic medicine students, and medical faculty. Lectures were scheduled in both required and elective courses and in other settings such as medical grand rounds, professional meetings, and interdisciplinary team conferences. Each of the 7 schools first presented the lecture to the health professional schools within their own institutions. Additional lectures were scheduled through word of mouth, typically through learners who had attended a lecture or learned about the program when results of the pilot program were presented at scientific meetings.

The case-based lecture was divided into 4 sections highlighting different perspectives of Part $\mathrm{D}$, each led by 1 of the 4 students. As shown in Table 1, the 4 topics included an overview of the Part D benefit and key stakeholder perspectives including insurers, patient, and provider perspectives. Cost-saving strategies were illustrated in the case presentation, including how to convert brand name drugs to therapeutically equivalent generic medications, change patient enrollment into a new Part D plan, and prescribe 90-day supplies of prescriptions for low-income subsidy patients. At the end of each of the 4 sections, there was an interactive question-and-answer session for learners.

\section{Survey}

All 7 schools distributed an anonymous pre/post survey (Appendix) to learners before and after each lecture. Completion of the survey was voluntary. Most survey questions had been assessed for face, content, and external validity in a previous study. ${ }^{12}$ New questions were tested for face validity by 2 separate groups of 13-15 resident physicians during the pilot phase of the present study.

The pre-intervention survey asked participants for nonidentifiable demographic information, including age, gender, health professional school or department, affiliation, and a description of prior academic or professional training in Part D, if any. Learners were then asked to rate their agreement regarding 11 statements from 3 key domains: knowledge about the Part $\mathrm{D}$ benefit and strategies to help low-income Part D patients (4 items), opinion of pharmacists' roles and contributions to the health care team ( 2 items), and intent to collaborate with pharmacists (5 items). A 4-point Likert scale was used to rate agreement ( $4=$ strongly agree, $3=$ somewhat agree, $2=$ somewhat disagree, 1 = strongly disagree) .

The post-intervention survey asked learners to rate their level of agreement with the 11 statements after attending the lecture. The same 4-point Likert scale was used to measure the learners' opinion of the peer-to-peer format (e.g., "I think this type of peer-to-peer lecture, where students teach other

\section{TABLE 1 Description of the Part D Lecture}

Speaker 1: Overview

Brief overview of Medicare (Parts A, B, C, and D)

History of Part D

Description of the basic Part D plan

Ways patients obtain Part D coverage

Scope of Part D coverage

Special problems facing vulnerable populations

Limitations of Part D

Speaker 2: Insurer perspective

Case presentation from insurer's perspective

Insurance marketplace and trends

Impact of Part D on insurance

Speaker 3: Patient perspective

Case presentation from the patient's perspective, including barriers to

obtaining coverage among low-income patient populations

Impact of Part D on Medicare patients

Speaker 4: Provider perspective

Case presentation from the provider's perspective

Resources and strategies for providers to help their patients gain access to cost-effective drug plans and medications

Impact of Part D on prescribers

${ }^{a}$ Clinically relevant and practical strategies that clinicians could incorporate into their practices were emphasized by all speakers. These included but were not limited to the following: specific cost-savings strategies such as 90-day supplies for prescriptions, use of generic medications, the Medicare Part D website, facilitating the application for the low-income subsidy, and telephone resources.

health professional students and residents, is an effective way to provide education") and the lecture's ability to promote collaboration (e.g., "I think that this type of peer-to-peer lecture promotes collaboration among health professionals"). In addition, the post-intervention survey contained two 5-point Likert-scale questions about the quality of the session, including "What did you think of the overall quality of instruction in today's lecture?" (rated from $5=$ excellent to $1=$ poor) and "How useful was the information you learned today?" (rated from $5=$ extremely useful to $1=$ not at all useful). Two open-ended questions were included for learners to comment on what they liked best about the lecture and how they thought it could be improved.

\section{Statistical Analysis}

Descriptive statistics were used to summarize learners' demographic characteristics and present frequency distributions of responses. The pre-intervention and post-intervention surveys were on opposite sides of the same page to enable measurement of differences in pre/post ordinal data using the Wilcoxon signed-rank test for 2 related samples. The Bonferroni method was used to adjust the a priori significance level to 0.004 (alpha of $0.05 \div k$ independent hypotheses, with $k=11$ to reflect the planned analyses of 11 items of interest), in the context of multiple comparisons. Data analyses were performed using SPSS software, version 18.0 (SPSS, Inc., Chicago, IL). 
Exclusions $(n=145)$ :

- Pharmacy students $(n=66)$

- Pharmacy faculty $(n=20)$

- Pharmacy residents $(n=19)$

- Nonprescribing faculty $(n=15)$

- Research/administrative staff $(n=11)$

- Social workers $(n=7)$

- Visiting physicians (not licensed in United States) $(n=3)$

- Missing affiliation information $(n=3)$

- Dentistry fellow $(n=1)$
Future Prescribers $(n=938)$ :

- Nurse practitioner students $(n=304)$

- Physician assistant students $(n=242)$

- Doctor of osteopathic medicine students $(n=228)$

- Doctor of medicine students $(n=164)$

Current Prescribers $(n=552)$

- Medical residents $(n=279)$

- Medical interns $(n=156)$

- Attending physicians $(n=90)$

- Nurse practitioners $(n=26)$

- Physician assistant $(n=1)$

aAll learners were asked to complete both sides of the 1-page, 2-sided pre-intervention and post-intervention survey (see Appendix).

\section{Results}

Between October 2008 and May 2010, trained pharmacy students from 7 California schools of pharmacy gave 58 presentations to audiences ranging from 4 to 109 learners, with at least 3 lectures given at each school. As all schools were located in California, the majority of lectures were given in California; however, peer educators from 1 school were invited to give 4 lectures at major academic medical centers in New York City and 4 lectures at major academic medical centers in Boston. As shown in Figure 1, a total of 1,635 learners attended the lectures and completed the survey, with response rate estimates averaging between 95\%-100\% across schools. Because the target audience was current or future prescribers, learners who did not meet this criterion $(n=142)$ were excluded from the analyses. Three learners who had missing affiliation information were excluded, leaving a study sample of 1,490 respondents.

The majority of learners ( $\mathrm{n}=938,63.0 \%)$ were health professional students, including nurse practitioner students $(n=304)$ and physician assistant students $(n=242)$. Resident physicians made up the largest group of the current prescribers $(n=279)$. The mean (SD) age of all learners was 31.2 (7.8) years, and $61.8 \%(\mathrm{n}=921)$ were female. Forty-two percent of the learners $(n=622,41.7 \%)$ reported no prior academic or professional training in Part D prior to the lecture, and only $14.8 \%(n=220)$ reported previous exposure to Part D through their health professional coursework.

The self-assessed baseline knowledge of learners was very low, with only 5\%-14\% strongly agreeing with statements assessing their knowledge of Part D (Table 2). In the intentto-collaborate domain, small proportions of learners strongly agreed with the statements that they collaborate with phar- macists and/or pharmacy students on drug policy (10.3\%), insurance plans (10.8\%), drug costs (15.1\%), drug formularies (22.0\%), and drug selection (23.6\%). Baseline agreement from learners was highest in the domain measuring attitude toward pharmacists. In this domain, $44.7 \%$ of learners strongly agreed that they think of pharmacists as patient advocates, and $62.7 \%$ strongly agreed that they understand how pharmacists provide value to the health care team.

Post-lecture analysis showed that more than $60 \%$ of participants strongly agreed with all statements on the survey instrument (Table 2). Of the 11 survey items, 9 showed statistically significant improvement from baseline $(P<0.001)$, including all items in the knowledge and intent-to-collaborate domains. The 2 items that did not improve significantly, understanding how pharmacists provide value to the health care team and whether pharmacists are viewed as patient advocates, were already high at baseline. Outcomes were similar across all schools when stratified by which pharmacy school delivered the lecture (data not shown). In addition, outcomes remained similar when these data were stratified by learner characteristics, which included gender, age, prescribing status, and health professional school affiliation (data not shown).

Learners rated the overall quality of instruction as high, with $58.7 \%$ rating it "excellent" and 31.6\% rating it "very good." Similarly, $46.5 \%$ rated the information presented as "extremely useful," and $41.3 \%$ rated the information presented as "very useful." Additionally, 97.7\% of learners strongly or somewhat agreed that they would recommend the lecture to other health professionals; $98.3 \%$ strongly or somewhat agreed the peer-topeer format was an effective way to provide education about Medicare Part D; and 98.4\% strongly or somewhat agreed that the peer-to-peer lecture promoted collaboration among health professionals. 


\begin{tabular}{|c|c|c|c|c|}
\hline Statement ${ }^{b}$ & $\begin{array}{l}\text { Number } \\
\text { Responding }\end{array}$ & $\begin{array}{l}\text { Strongly Agree } \\
\text { Pre } \mathrm{n}(\%)\end{array}$ & $\begin{array}{l}\text { Strongly Agree } \\
\text { Post } \mathbf{n}(\%)\end{array}$ & $P$ Value ${ }^{d}$ \\
\hline \multicolumn{5}{|l|}{ Attitude toward pharmacists domain } \\
\hline - I understand how pharmacists provide value to the health care team. & 1,432 & $898 \quad(62.7)$ & $906 \quad(63.3)$ & 0.92 \\
\hline - I think of pharmacists as patient advocates. & 1,473 & $659 \quad(44.7)$ & $957 \quad(65.0)$ & 0.02 \\
\hline \multicolumn{5}{|l|}{ Knowledge domain } \\
\hline - I understand the Medicare Part D benefit. & 1,472 & $(4.9)$ & $944 \quad(64.1)$ & $<0.001$ \\
\hline $\begin{array}{l}\text { - I can identify challenges and barriers that confront low-income individuals } \\
\text { regarding Medicare Part D. }\end{array}$ & 1,433 & $204 \quad(14.2)$ & $891 \quad(62.2)$ & $<0.001$ \\
\hline - I can identify key Medicare Part D resources to help my patients. & 1,465 & $97 \quad(6.6)$ & $893(60.9)$ & $<0.001$ \\
\hline - I consider a patient's Medicare Part D status when making prescribing decisions. ${ }^{e}$ & 1,066 & $115 \quad(10.8)$ & $681 \quad(63.8)$ & $<0.001$ \\
\hline \multicolumn{5}{|l|}{ Intent-to-collaborate domain } \\
\hline \multicolumn{5}{|l|}{ - I consult with pharmacists and/or pharmacy students about:e } \\
\hline a. drug selection & 1,149 & $271 \quad(23.6)$ & $705 \quad(61.4)$ & $<0.001$ \\
\hline b. drug costs & 1,127 & $170 \quad(15.1)$ & $755 \quad(67.0)$ & $<0.001$ \\
\hline c. drug formularies & 1,124 & $247 \quad(22.0)$ & $744 \quad(66.2)$ & $<0.001$ \\
\hline d. drug policy (e.g., Medicare Part D) & 1,098 & $113 \quad(10.3)$ & $701 \quad(63.8)$ & $<0.001$ \\
\hline e. insurance plans & 1,098 & $119 \quad(10.8)$ & $663 \quad(60.4)$ & $<0.001$ \\
\hline \multicolumn{5}{|c|}{$\begin{array}{l}\text { aLikert-scale data }(1=\text { strongly disagree, } 4=\text { strongly agree). Results in this table represent a binary variable-strongly agree versus all other categories combined. } \\
\text { bSee Appendix for text of survey statements. } \\
{ }^{c} \text { For each item, only learners with complete pre-intervention and post-intervention data were included in the analysis. } \\
d^{d P} \text { values were derived from the Wilcoxon signed-rank test for } 2 \text { related samples, with a Bonferroni-adjusted significance level of } 0.004 \text { because of multiple comparisons. } \\
\text { Although the table columns represent a binary measure, statistical testing was performed on the original } 4 \text {-category Likert-scale data. } \\
{ }^{e} \text { Reduced response rates reflect the addition of a choice of "nonapplicable" for these statements, in order to account for students early in their training. }\end{array}$} \\
\hline
\end{tabular}

The majority of learners $(n=912,61.2 \%)$ provided optional written comments, and representative comments from learners are shown in Table 3. Almost all comments $(n=873,95.7 \%)$ contained positive feedback about the presentation, and $22.6 \%$ ( $n=206)$ of those making a comment gave constructive feedback about how the presentation could be improved. The most common positive comment focused on the content of the lectures. Learners particularly valued the use of cases and examples and the clinical relevance of the material. Learners also provided positive feedback about the innovative design and delivery of the lecture, the use of pharmacy students as peer educators, and the multiple stakeholder perspectives represented. For those learners providing constructive feedback on how the lecture could be improved, the most prevalent themes were the need to expand the time allotted for the lecture and for answering learners' questions, and the desire for more casebased examples and additional lecture content.

\section{Discussion}

This multisite study revealed that at baseline, there is a widespread lack of understanding of Part D among current and future prescribers, which could potentially prevent these professionals from helping their patients navigate and realize the benefits of this confusing program. We found that across sites, an efficient 1- to 2-hour lecture delivered by pharmacy student peer educators was associated with significant increases in learners' self-reported knowledge about Medicare Part D, thus raising self-awareness about cost-saving strategies for Part D patients, and highlighting the role of pharmacists in Part D education.

Health care providers, particularly physicians, are in a unique position to address patients' concerns about out-ofpocket drug costs ${ }^{20,21}$; the importance of physicians talking with patients about drug cost issues has been well documented. ${ }^{21-23}$ Yet, in 1 study of Part $\mathrm{D}$ beneficiaries with diabetes, less than one-half of patients discussed drug costs with their physicians. ${ }^{24}$ Another study found that $40 \%$ of physicians reported that, at least once in the previous 30 days, they had not discussed cost with their patients but wished they had..$^{25}$ The authors concluded that physicians' perception of their knowledge of medication costs may be an important factor in initiating cost discussions, where more awareness by physicians about drug costs leads to more discussions with patients about drug costs..$^{25}$

In addition, Part D beneficiaries have numerous prescription drug plan options from which to choose, and each plan has a different cost structure and formulary. The lack of knowledge about Part D among many health care trainees and providers and the complexity of the benefit highlight the need for medical schools and residency programs to develop 


\section{TABLE 3 Summary of Learners' Written Comments}

Positive comments on the content of the lecture

- Third-year medical student: "It will help us as future physicians to be better patient advocates and more conscientious about assessing our patients' drug costs."

- Second-year nurse practitioner student: "I learned invaluable information about how to immediately save patients' money on their drug costs."

- Resident physician: "It was a clarification of a topic that is not covered in our curriculum, yet is one that affects a large number of our patients."

- Attending physician: "I thought the Part D overview was excellent and having the discussion with case studies brings the message home in a very effective way for physicians."

Positive comments on the lecture's innovative format and delivery

- Second-year medical student: "This is the kind of interdisciplinary interaction I was looking forward to when I applied to this school. I especially liked the student presenters engaging the audience and the well-organized presentation."

- Second-year physician-assistant student: "I so value and appreciate hearing from our pharmacy peers. I really hope to be able to utilize pharmacy specialists once I begin practicing."

- Resident physician: "Presenting multiple stakeholder perspectives made it feel unbiased."

Constructive feedback to improve the lecture

- Second-year physician assistant student: "Would like a follow-up meeting to discuss issues and questions that came up after the lecture; for example, what options do patients have for cost comparison if they are not in Medicare Part D?"

- Fourth-year medical student: "More patient examples, more time for questions, more time for the lecture in general."

- Resident physician: "Maybe you could come back and we could have more interactive and smaller workshops where we can talk to you more about problems we face with our clinic patients."

targeted teaching about this topic. The Part D content presented in the present study's lecture may enable learners to question their patients' ability to afford medications and, if necessary, counsel and direct them to pharmacists and other Part $\mathrm{D}$ resources. Although the present study found clear statistical improvements from pre- to post-intervention in the proportions of learners who would consider their patients' Medicare Part D insurance status when making prescribing decisions, it is unclear if this change would translate into actual behavioral changes.

Further underscoring the importance of health policy education are the recent calls by physician and policy experts for increased health policy education early in medical training. ${ }^{5-7}$ With the skyrocketing costs of health care and prescription drugs and the cost burdens faced by many underserved older adults who rely on Part D for their prescription drugs, it is academia's responsibility to teach timely health care systems content so that current and future prescribers can better serve their patient populations. Systems-based knowledge about topics such as health services delivery and cost-savings strategies are critical as schools and training programs prepare medical students and resident physicians to deliver fiscally responsible, patient-centered medicine to an increasingly aging population. Medical educators have been slow to incorporate teaching about cost-containment strategies into the formal medical education curriculum, despite widespread acknowledgement of this need. ${ }^{5}$ The educational initiative described in this article is a step toward meeting that need.

After the delivery of the lecture, there was an increase in learners' intent to collaborate with pharmacists in key activities such as drug selection, drug costs, formularies, Part D, and insurance. We believe that measuring respondents' intent to collaborate is an important attitudinal assessment that was relevant to this study; however, we acknowledge that we have no evidence to support whether this perception translated into actual improvements in collaborative care. It is intriguing that intent to collaborate with pharmacists increased significantly even though $63 \%$ of the learners already understood how the pharmacist could contribute to the health care team at baseline. Our pharmacy-student lecture may have contributed to this positive outlook on interprofessional collaboration by raising audiences' awareness of pharmacists' scope of practice and roles in patient care. Interprofessional audiences were provided with specific information regarding how pharmacists can help with patient care in regards to Medicare Part D; for example, assisting with cost-savings strategies and medication management. Our pharmacy students also led an interactive case study of a chronically ill patient with Medicare Part D, engaging the audience to identify barriers to medication access and to problem solve together. This finding indicates that large classroombased initiatives, such as the interprofessional peer education teaching model described in this article, may provide a first step toward promoting collaboration among health professions, while using few resources. ${ }^{26}$

While the focus of this study was on a peer-to-peer model using student pharmacists as educators for health professional students and trainees in residency, this pharmacist-led model may also prove effective in educating existing prescribers in large managed care organizations through such venues as grand rounds or continuing education. Consideration could also be given to implementing a similar educational program in managed care settings wherein pharmacists could be trained to 
educate other health professionals about Part D and drug cost containment strategies. Finally, as more health policy changes from the PPACA begin to affect practice, other interprofessional peer educator lectures could be developed to enhance pharmacist-prescriber collaborative care in medication therapy management programs, accountable care organizations, patient-centered medical homes, and transitions-of-care interventions. ${ }^{15}$

\section{Limitations}

Due to time constraints, we relied on self-assessment of Part D knowledge rather than objective measures. Using objective measures would reduce responder bias and provide a more accurate assessment of actual knowledge acquired from the lecture. Further, we were not able to collect follow-up data on learners' retention of knowledge and attitudes. Without this information, we are unable to determine if the improvements in the attitudes, knowledge, or intent-to-collaborate domains translated into behavioral changes. Finally, the study design did not include a comparison group; as a result, we could not evaluate the effectiveness of this peer education program compared with more typical teaching models.

\section{Conclusions}

This multisite study, which examined the impact of Medicare Part D training by pharmacy students to learners in other professions, showed increases in self-reported learner awareness of drug cost containment strategies for Part D patients and improvements in self-assessed knowledge of Part D, attitudes toward pharmacists, and intentions to collaborate with pharmacists. While additional work is warranted to see if similar interventions change clinical practice, these initial results suggest that this program may be used as a model for future dissemination of critical and timely health policy information to a wide variety of health professional students and resident physicians.

\section{Authors}

CINDY J. LAI, MD, is Associate Professor of Clinical Medicine, UCSF School of Medicine, San Francisco, California; AMANDA R. SMITH, MPH, is Research Analyst and Program Director, Partners in D, UCSF School of Pharmacy; MARILYN R. STEBBINS, PharmD, is Clinical Professor of Pharmacy, UCSF School of Pharmacy; TIMOTHY W. CUTLER, PharmD, is Associate Professor of Clinical Pharmacy, UCSF School of Pharmacy; and HELENE L. LIPTON, PhD, is Professor of Health Policy, UCSF Schools of Pharmacy and Medicine, San Francisco, California.

AUTHOR CORRESPONDENCE: Cindy J. Lai, MD, Associate Professor of Clinical Medicine, UCSF School of Medicine, 505 Parnassus Ave., M1078, San Francisco, CA 94143. Tel: 415.476.1964; Fax: 415.502.7544; E-mail: clai@medicine.ucsf.edu.

\section{DISCLOSURES}

This work was supported by a grant from the Amgen Foundation. The authors report no financial or other conflicts of interest related to the subject of this article.

Concept and design were performed primarily by Lipton, Cutler, and Stebbins, with assistance from Lai. Data were collected by Cutler, Smith, Stebbins, and Lipton. Data analysis was conducted primarily by Smith, with assistance from Cutler and Lipton. Data were interpreted primarily by Lai, Lipton, and Smith, with assistance from Cutler. The manuscript was written and revised primarily by Lai, Lipton, Smith, and Cutler.

\section{ACKNOWLEDGMENTS}

The authors would like to acknowledge the contributions of the investigators who participated in Partners in D, including Shirley M. Tsunoda, PharmD, University of California, San Diego, La Jolla, California; Vinay Patel, PharmD, Touro University California, Vallejo, California; Edith Mirzaian, PharmD, University of Southern California, Los Angeles, California; Joycelyn Mallari Yamzon, PharmD, Loma Linda University, Loma Linda, California; Rajul Patel, PharmD, PhD, University of the Pacific, Stockton, California; and Sam Shimomura, PharmD, Western University of Health Sciences, Pomona, California. The authors also give special thanks to all of the pharmacy students who participated as peer educators. We also acknowledge the UCSF Educational Scholarship Conference (ESCape) for its thoughtful input on the manuscript.

\section{REFERENCES}

1. Institute of Medicine. Retooling for an Aging America: Building the Health Care Workforce. Washington, DC: National Academy Press; 2008. Available at: http://www.nap.edu/catalog.php?record_id=12089. Accessed June 30, 2011

2. Accreditation Council for Graduate Medical Education. Common program requirements: general competencies. February 13, 2007. Available at: http:// www.acgme.org/outcome/comp/GeneralCompetenciesStandards21307.pdf. Accessed June 30, 2011

3. Liaison Committee on Medical Education. LCME accreditation standards. June 2008. Available at: http://www.lcme.org/functionslist. htm\#educational\%20objectives. Accessed June 30, 2011.

4. Association of American Medical Colleges. Educating doctors to provide high quality medical care: a vision for medical education in the United States. Report of the Ad Hoc Committee of Deans. July 2004. Available at: http://cgea.net/deansreport.pdf. Accessed June 30, 2011.

5. Cooke M. Cost consciousness in patient care-what is medical education's responsibility? N Engl J Med. 2010;362(14):1253-55. Available at: http:// www.nejm.org/doi/full/10.1056/NEJMp0911502. Accessed June 30, 2011.

6. Mou D, Sarma A, Sethi R, Merryman R. The state of health policy education in U.S. medical schools. N Engl J Med. 2011;364(10):e19. Available at: http://www.nejm.org/doi/full/10.1056/NEJMpl101603. Accessed June 30, 2011.

7. Patel MS, Davis MM, Lypson ML. Advancing medical education by teaching health policy. N Engl J Med. 2011;364(8):695-97. Available at: http:// www.nejm.org/doi/full/10.1056/NEJMpl009202. Accessed June 30, 2011

8. Centers for Medicare and Medicaid Services. Estimated financial effects of the "Patient Protection and Affordable Care Act," as amended. April 22, 2010. Available at: www.cms.gov/ActuarialStudies/Downloads/ PPACA_2010-04-22.pdf. Accessed June 30, 2011.

9. Mott DA, Thorpe JM, Thorpe CT, Kreling DH, Gadkari AS. Effects of Medicare Part D on drug affordability and utilization: are seniors with prior high out-of-pocket drug spending affected more? Res Social Adm Pharm. 2010;6(2):90-99. 
10. Shrank WH, Asch SM, Joseph GJ, et al. Physicians' perceived knowledge of and responsibility for managing patients' out-of-pocket costs for prescription drugs. Ann Pharmacother. 2006;40(9):1534-40.

11. Gruber J. Choosing a Medicare Part D plan: are Medicare beneficiaries choosing low-cost plans? The Henry J. Kaiser Family Foundation. March 2009. Available at: http://www.kff.org/medicare/upload/7864.pdf. Accessed June 30, 2011.

12. Lipton HL, Lai CJ, Cutler TW, Smith AR, Stebbins MR. Peer-to-peer interprofessional health policy education for Medicare Part D. Am J Pharm Educ. 2010;74(6):102. Available at: http://www.ncbi.nlm.nih.gov/pmc/articles/PMC2933011/pdf/ajpe102.pdf. Accessed June 30, 2011.

13. Catlin A, Cowan C, Hartman M, Heffler S; National Health Expenditure Accounts Team. National health spending in 2006: a year of change for prescription drugs. Health Aff (Millwood). 2008;27(1):14-29. Available at: http:// waysandmeans.house.gov/media/pdf/110/catlin.pdf. Accessed June 30, 2011

14. Cutler TW, Stebbins MR, Smith AR, Patel RA, Lipton HL. Promoting access and reducing expected out-of-pocket prescription drug costs for vulnerable Medicare beneficiaries: a pharmacist-directed model. Med Care. 2011;49(4):343-47.

15. H.R. 3590-11lth Congress: Patient Protection and Affordable Care Act. 2009. GovTrack.us. Available at: http://www.govtrack.us/congress/bill. xpd?bill=h111-3590. Accessed June 30, 2011.

16. U.S. Government Accountability Office. Prescription drugs: trends in usual and customary prices for commonly used drugs. Report No. GAO-11306R. February 10, 2011. Available at: www.gao.gov/new.items/d11306r.pdf. Accessed June 30, 2011.

17. Chisholm-Burns MA, Kim Lee J, Spivey CA, et al. US pharmacists' effect as team members on patient care: systematic review and meta-analyses. Med Care. 2010;48(10):923-33. Available at: http://journals.lww.com/lww-medicalcare/Fulltext/2010/10000/US_Pharmacists__Effect_as_Team_Members_ on_Patient.10.aspx. Accessed June 30, 2011.
18. Lockspeiser TM, O'Sullivan P, Teherani A, Muller J. Understanding the experience of being taught by peers: the value of social and cognitive congruence. Adv Health Sci Educ Theory Pract. 2008;13(3):361-72.

19. Partners in D: Pharmacists helping you get the most out of Medicare drug benefits. Learn about the program. Available at: http://www.partnersind.com/learn/. Accessed June 30, 2011.

20. Federman AD, Alexander GC, Shrank WH. A practical physician's guide to the Medicare drug benefit plan. Mayo Clin Proc. 2006;81(9):1217-21. Available at: http://www.mayoclinicproceedings.com/content/81/9/1217.full. pdf + html. Accessed June 30, 2011

21. Tseng CW, Dudley RA, Brook RH, et al. Elderly patients' preferences and experiences with providers in managing their drug costs. J Am Geriatr Soc. 2007;55(12):1974-80

22. Alexander GC, Casalino LP, Meltzer DO. Patient-physician communication about out-of-pocket costs. JAMA. 2003;290(7):953-58. Available at: http://jama.ama-assn.org/content/290/7/953.long. Accessed June 30, 2011.

23. Wilson IB, Schoen C, Neuman P, et al. Physician-patient communication about prescription medication nonadherence: a 50-state study of America's seniors. J Gen Intern Med. 2007;22(1):6-12. Available at: http://www.ncbi. nlm.nih.gov/pmc/articles/PMC1824770/?tool=pubmed. Accessed June 30, 2011

24. Schmittdiel JA, Steers N, Duru OK, et al. Patient-provider communication regarding drug costs in Medicare Part D beneficiaries with diabetes: a TRIAD Study. BMC Health Serv Res. 2010;10:164. Available at: http://www. biomedcentral.com/content/pdf/1472-6963-10-164.pdf. Accessed June 30, 2011

25. Beran MS, Laouri M, Suttorp M, Brook R. Medication costs: the role physicians play with their senior patients. J Am Geriatr Soc. 2007;55(1):102-07.

26. Curran VR, Sharpe D, Flynn K, Button P. A longitudinal study of the effect of an interprofessional education curriculum on student satisfaction and attitudes towards interprofessional teamwork and education. J Interprof Care. 2010;24(1):41-52. 


\section{APPENDIX Pre-Intervention and Post-Intervention Survey Instruments}

Peer-to-Peer Presentation:

[SITE] [SCHOOL/DEPARTMENT], [DATE]

1. In which school/program do you belong?

\begin{tabular}{|c|c|c|c|c|c|}
\hline O & Medicine & $O$ & Physician Assistant & $\mathrm{O}$ & None \\
\hline O & Nursing & $\bigcirc$ & Dentistry & \multirow[t]{2}{*}{$\bigcirc$} & \multirow[t]{2}{*}{ Other (specify) } \\
\hline$\bigcirc$ & Pharmacy & $\bigcirc$ & Osteopathic Medicine & & \\
\hline
\end{tabular}

2. What best describes your affiliation with the school/program? (Bubble in all that apply)
1st year Student
2nd year Student
3rd year Student
4th year Student
5th year Student or Higher

Nurse Practitioner Student

Masters Student

$\bigcirc$ PhD Student

$\bigcirc$ Intern $\bigcirc$ Resident

Faculty (with prescribing authority)

Faculty (without prescribing authority)

Other (specify):

3. What is your age? years

4. What is your gender? O Female O Male

5. Which of the following describes your Medicare Part D experience? (Bubble in all that apply)
O NONE
Prior instruction in one of my courses
Work experience
Personal experience (self/friends/family)
Read/heard stories through the media or in scientific journals
Other experience (please specify):

Please fill in the correct bubble indicating how much you agree or disagree with the statements:

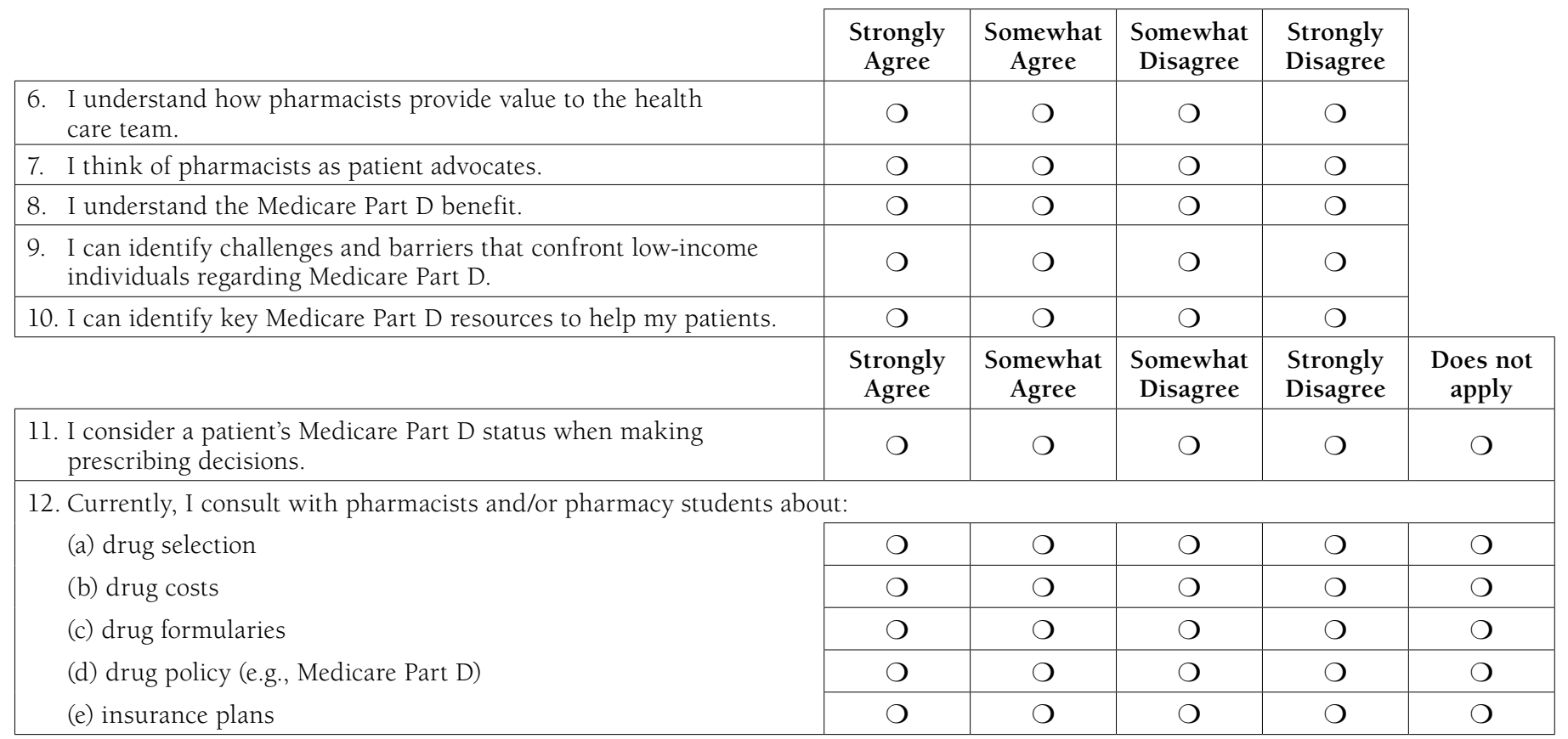




\section{APPENDIX Pre-Intervention and Post-Intervention Survey Instruments (continued)}

13. What did you think of the overall quality of instruction in today's lecture?
O Poor
Fair
O Good
V Very Good
Oxcellent

14. How useful was the information you learned today?

$\bigcirc$ Not at all $O$ A little $\bigcirc$ Moderately $\bigcirc$ Very $\bigcirc$ Extremely

Please fill in the correct bubble indicating how much you agree or disagree with the statements:

\begin{tabular}{|c|c|c|c|c|}
\hline & $\begin{array}{l}\text { Strongly } \\
\text { Agree }\end{array}$ & $\begin{array}{l}\text { Somewhat } \\
\text { Agree }\end{array}$ & $\begin{array}{l}\text { Somewhat } \\
\text { Disagree }\end{array}$ & $\begin{array}{l}\text { Strongly } \\
\text { Disagree }\end{array}$ \\
\hline $\begin{array}{l}\text { 15. I think this type of Peer-to-Peer lecture, where students teach } \\
\text { other health professional students and residents, is an effective } \\
\text { way to provide education. }\end{array}$ & $\bigcirc$ & $\bigcirc$ & $\bigcirc$ & $\bigcirc$ \\
\hline $\begin{array}{l}\text { 16. I think this type of Peer-to-Peer lecture promotes collaboration } \\
\text { among health professionals. }\end{array}$ & $\bigcirc$ & $\bigcirc$ & $\bigcirc$ & $\bigcirc$ \\
\hline $\begin{array}{l}\text { 17. I would recommend this lecture to other health professional } \\
\text { students and residents. }\end{array}$ & ○ & $\bigcirc$ & $\bigcirc$ & $\bigcirc$ \\
\hline
\end{tabular}

As a result of this lecture...

\begin{tabular}{|c|c|c|c|c|c|}
\hline $\begin{array}{l}\text { 18. I better understand how pharmacists provide value to the health } \\
\text { care team. }\end{array}$ & $\bigcirc$ & $\bigcirc$ & $\bigcirc$ & $\bigcirc$ & \\
\hline 19. I am more likely to think of pharmacists as patient advocates. & $\bigcirc$ & $\bigcirc$ & $\bigcirc$ & $\bigcirc$ & \\
\hline 20. I better understand the Medicare Part D benefit. & $\bigcirc$ & $\bigcirc$ & $\bigcirc$ & $\bigcirc$ & \\
\hline $\begin{array}{l}\text { 21. I can better identify challenges and barriers that confront } \\
\text { low-income individuals regarding Medicare Part D. }\end{array}$ & $\bigcirc$ & $\bigcirc$ & $\bigcirc$ & $\bigcirc$ & \\
\hline \multirow[t]{2}{*}{$\begin{array}{l}\text { 22. I can better identify key Medicare Part D resources to help } \\
\text { patients. }\end{array}$} & $\bigcirc$ & $\bigcirc$ & $\bigcirc$ & $\bigcirc$ & \\
\hline & $\begin{array}{l}\text { Strongly } \\
\text { Agree }\end{array}$ & $\begin{array}{l}\text { Somewhat } \\
\text { Agree }\end{array}$ & $\begin{array}{l}\text { Somewhat } \\
\text { Disagree }\end{array}$ & $\begin{array}{l}\text { Strongly } \\
\text { Disagree }\end{array}$ & $\begin{array}{l}\text { Does not } \\
\text { apply }\end{array}$ \\
\hline $\begin{array}{l}\text { 23. As a result of this lecture, I am more likely to consider a patient's } \\
\text { Medicare Part D status when making prescribing decisions. }\end{array}$ & $\bigcirc$ & O & $\bigcirc$ & $\bigcirc$ & $\bigcirc$ \\
\hline \multicolumn{6}{|c|}{ 24. As a result of this lecture, I am more likely to consult with pharmacists and/or pharmacy students about: } \\
\hline \multirow{5}{*}{$\begin{array}{l}\text { (a) drug selection } \\
\text { (b) drug costs } \\
\text { (c) drug formularies } \\
\text { (d) drug policy (e.g., Medicare Part D) } \\
\text { (e) insurance plans }\end{array}$} & $\mathrm{O}$ & 0 & 0 & 0 & 0 \\
\hline & $O$ & $O$ & $O$ & $\bigcirc$ & $\bigcirc$ \\
\hline & $\mathrm{O}$ & 0 & 0 & 0 & 0 \\
\hline & 0 & $\bigcirc$ & $\bigcirc$ & $\bigcirc$ & $\bigcirc$ \\
\hline & $O$ & 0 & $O$ & 0 & $\mathrm{O}$ \\
\hline
\end{tabular}

25. What did you like best about this lecture?

26. How can this lecture be improved? 